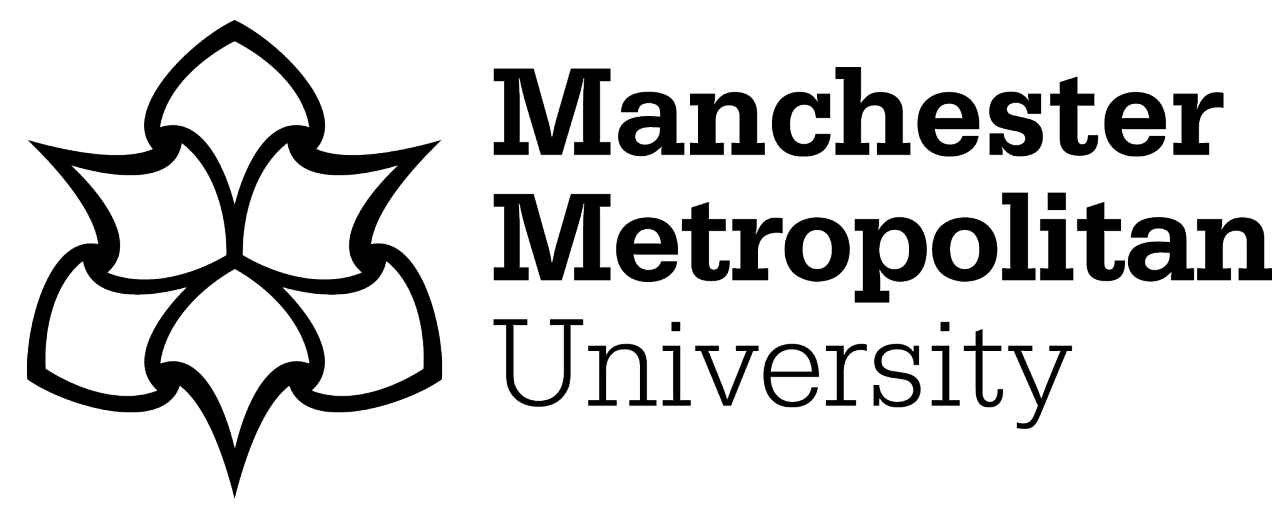

Di Ciolla, Nicoletta and Pasolini, Anna (2018) The Violent Mother in Fact and Fiction. In: Domestic Noir: The New Face of 21st Century Crime Fiction. Palgrave MacMillan, pp. 137-158. ISBN 3319693387

Downloaded from: https://e-space.mmu.ac.uk/622609/

Version: Accepted Version

Publisher: Palgrave MacMillan

DOI: https://doi.org/10.1007/978-3-319-69338-5

Please cite the published version 


\title{
The Violent Mother in Fact and Fiction
}

\author{
Nicoletta Di Ciolla (Manchester Metropolitan University, UK) \\ Anna Pasolini (University of Milan, ITA)
}

Representations in popular culture have a tendency to configure women as gentler by nature, as caring nurturers, whose physiological predisposition to take care of others is antecedent to any external intervention of cultural norms and practices that mould them into that shape. The imagined constant of the female constitution is believed to find its highest possible level of expression in motherhood, a state of being to which a set of regulatory traits are attributed that include unconditional love, abnegation, selflessness and self-sacrifice, in the name of children and family. This view, challenged from many quarters because it is considered limiting, and reflective of the oppression and control exercised on women by the patriarchal order, continues however to chime with the most prevalent popular discourses on gender. ${ }^{1}$

The mere observation of reality, however, reveals a more complex picture of femalehood and motherhood, and evidence of deviation from this reassuring (stereo)type. The association between women and violence appears in an increasing variety of permutations in media reports. Here, in addition to the 'traditional' scenarios, where women are placed at the receiving end of episodes of aggression (familial abuses, harassments, sexual crimes, and even murders), occurrences of a less customary figure are claiming a space: that of the female often a mother - who is herself responsible for inflicting harm. ${ }^{2}$ A similar articulation of this aspect of female experience is found in literary fiction and TV narratives. Stories featuring characters of 'mothers who damage' - through forms of abuse or neglect that go from minor to severe - reflect a growing public concern for behavioural dynamics which are universally considered as uncharacteristic, hence dysfunctional and profoundly disconcerting, but simultaneously enable readers and viewers to exorcise those concerns, and the disturbance they encode, by situating them in a textual or televisual elsewhere.

This chapter analyses the representation of three 'atypical' mother figures in several contemporary European, female-authored novels, published between 2001 and 2014. We take 'atypical' as an operative definition to signify mothers whose behaviour does not seem to conform with the socially constructed, culturally transmitted and collectively understood models, and commit - or are considered to have committed - acts that can be generically 
defined as violent, usually affecting and causing damage to children. To clarify the terms of these behavioural models, we will refer to some indicative criminological and philosophical positions that have addressed and problematized the question of gender(ed) violence. It is our contention that narrative fiction, with its mass reach, can contribute to the deconstruction of the fixed paradigms that continue to be in place in the categorization and evaluation of female behaviour and, through its contribution, can support positive cultural and social changes. Crime fiction is an especially effective tool for this purpose: its popular appeal makes it one of the primary sources through which the general public get their ideas about crime in society ${ }^{3}$ and, its facility for interpreting and giving a voice to social and cultural discomfort renders it capable of expressing dissent and triggering in its audiences an appetite for change. ${ }^{4}$ It is a fact that authors of fiction find inspiration for stories, situations, and characters in real life events, and that they are attuned to the debates that take place amongst practitioners - of law, criminal justice, or criminology - to which they refer in the name of factual accuracy and authenticity. We want to argue that this should not be considered as one-way traffic, and that the potential of fiction to support practitioners, as well as the general public, in their understanding of offenders and their crimes, should not be underestimated or underexploited. ${ }^{5}$ Fiction can help us understand actual experience, bringing to the fore a range of factors that go beyond the criminal act itself, enabling a greater appreciation of what shapes crime and criminal justice, and a better understanding of perpetrators. Popular representations of crime, and discourses about crime that can be found in novels - or on $\mathrm{TV}$, or in new media - raise a number of relevant ethical and philosophical issues that have wider resonance, because of their bigger audience, than academic criminology. Because of this, they are useful to society at large. ${ }^{6}$

Fictional representations of women's problematic relations to motherhood arising from and/or triggering forms of domestic violence can induce a reflection on established cultural expectations of 'proper' maternal behaviours, on the assumption that women have chief responsibility for child rearing and wellbeing, and they alone are to blame if anything goes wrong. Observing how the problematic relation to motherhood is expressed in narrative fiction offers a wider span of examples of women's agency in situations of violence within the family (specifically against children), which go beyond entrenched stereotypes of the violent mother as 'mad' or solely as reacting to victimisation. This underlines the suitability of narrative fiction as a reliable partner for all those disciplines in the social sciences that are concerned with understanding the dynamics of social relations, and with removing inequalities that develop from the unequal distribution of power and influence. In the specific context of motherhood, this synergy facilitates a repositioning of the question of what a mother is (or should be), away 
from outdated gender essentialist positions, and into a space where individual experiences can be interpreted free from prejudicial premises and clichés.

\section{Can women and mothers really be bad? From positivist criminology and intersectionality, to narrative fiction.}

The dominant and widely shared assumptions on gender and motherhood that set the parameters within which female and motherly behaviour could be expressed - with the endorsement of various theoretical frameworks - have for a long time prevented an understanding of the phenomenon of maternal violence beyond a summary moral judgement, condemnation, denial, or the unleashing of social panic. The idea that women are not capable of being inherently violent was curiously shared by the traditional criminologists of the early $20^{\text {th }}$ century and later by some feminist scholars, albeit the premises leading to that conclusion were radically different. The idea of the positivist (and male) criminologists in the late 1800s and early 1900s that crime was gender specific, almost an epiphenomenon of maleness, contributed to the creation of a taxonomy of criminal ability in which women occupied the lower rungs. The works of Lombroso and Thomas affirmed the view that the capacity for criminal acts was physiologically irreconcilable with females, for reasons that included the fact that their brain, being smaller, was prone to psychological disturbances and dysfunctions, but not to wilful acts of violence. In combination with genetic predisposition, they argued, cultural conditioning contributed to rendering the female accustomed to behaving in a tame, gentle manner, hence less likely to offend. ${ }^{7}$ The view from the social sciences chimed with Freud's psychodynamic theory of female delinquency, which was also being developed at that time. ${ }^{8}$ Female offending was limited to crimes of the 'hidden' kind, and either went undetected, or was dealt with more leniently by a justice system blinded by preconceptions about women's intrinsic incapacity to commit crimes. ${ }^{9}$

Feminist criminology from the 1970s has shifted the debate away from the axioms of genetic determinism, problematizing these assumptions. Radical feminist scholars acknowledge that women can be violent, but ascribe this to a reaction to the systemic oppression that they suffer at the hand of patriarchal structures: in a context where they have little or no power, women find in violence an instrument of defence, and a survival strategy. ${ }^{10}$ The fact that their violence can be directed towards their children, it is argued, demonstrates 
that motherhood too is experienced by women as a colony of patriarchal power, as an institution, whose potential for empowering is reduced or suppressed. ${ }^{11}$

The challenge to the axiom of the innateness of the maternal instinct, and the belief that it is subject to societal pressures and expectations of role allocation, has demanded a reconceptualisation of the notion of the 'natural' aspect of maternal behaviour. This is what the works of authors such as Nancy Chodorow and Elisabeth Badinter have done, problematizing the concept of motherhood, focussing on the spectrum of its nuances, and developing the propositions that Simone De Beauvoir had expressed, with devastating poignancy, in her essays and in her novels thirty years earlier. ${ }^{12}$ The assumption that the interests of mothers should always and automatically coincide with those of her children also comes under scrutiny, urging a consideration that a mother's feelings towards her children could be affected by some degree of ambivalence. ${ }^{13}$ Work carried out from the early 2000s advocates an interdisciplinary approach that would include consideration of social pressures as well as the psychological and subjective factors that influence choices and behaviours. ${ }^{14}$ Such an 'intersectional ${ }^{15}$ approach reconciles different, hitherto neglected and seemingly contradictory 'points of intersection ${ }^{16}$ in women's - and mothers' - experience of violence, admitting the possibility that they can be, in the same context, both victims and willing perpetrators. It can account for the mobility of role positions and agency of women in the domestic environment; and it can explain why, forced to play the rules of the game, women may be victims in one situation (for example in relation to their partners or to the broader social structures), but turn into victimiser in relation to weaker elements, in primis their children. ${ }^{17}$ In our context the intersectional analysis of female violence highlights three key theoretical issues that merit scrutiny: firstly, the differences within the categories of 'women' and 'mothers', which posit that there is no universal womanhood or natural way of mothering; secondly, the multiplicity of female identity, which subsumes different, and oftentimes contradictory elements such as being a victim, a survivor and a victimiser; and finally the question of power, and the need to conceptualise it not only in terms of gender relations, but also in its mobilization through other channels, which produce complex systems of oppression activated even within the category of 'woman' itself. ${ }^{18}$

Similar issues emerge from the contemporary psychoanalytic perspectives, which seek to emphasise the interaction between psychological factors, cultural representations and the social management of motherhood, and focus on understanding maternal development ('maternal individuation') instead of looking at the relationship between mother and child from the standpoint of the latter, as traditional psychoanalysis has tended to do. ${ }^{19}$ This framework offers a way out of the 'impossible maternal ideals' ${ }^{20}$ which can generate in mothers resentment 
towards children, violence and abuse, and redefines maternal ambivalence so that a mother can discover 'ways of mothering which are congruent with her particular capacities and desires, rather than measuring herself against maternal mythologies. ${ }^{21}$

Whilst these debates animate discussion, and lead to paradigm-shifting discoveries in academic circles, however, they have had limited impact on societal attitudes with regard to what motherhood is, or should be. It is possible to argue that traditional gender stereotypes remain pervasive in public opinion, and continue to influence the way in which much popular culture represent women and mothers: still, in their essence, partners, mothers, and nurturers. Against this background of traditional wisdom, women in general - and mothers in particular - who do not conform to the iconic model, who transgress from the norm by displaying behaviour which reveals signs of aggression or violence are still considered an aberrant ontological and social anomaly. ${ }^{25}$ Their actions become the subject of extensive coverage and in-depth analysis in old and new media, generating attention that amplifies the natural shock that reasonably follows an act of violence, with the extra ignominy of the gender factor. But attempts to explain behaviour that is irreconcilable with expectations, and with the canonical gender stereotypes, usually results in the creation of yet more stereotypes. Violent female behaviour continues to be understood mostly as an effect of persistent victimisation, and nonstandard, violent mothers continue to be framed in legal and public discourses into two additional dominant categories besides that of victim: 'mad' or 'bad'. ${ }^{22}$ This is a reductionist view that effectively diminishes women's responsibility and culpability as individuals, whilst at the same time limiting their agency, and their level of control over their own lives.

Current data from the UK and the EU confirms that women are statistically less likely to commit crime than men, and that they constitute a very small proportion of the prison population. ${ }^{23}$ Their crimes tend to be less serious, 'victimless' (such as fraud, theft, drug related), and receive more lenient sentences, normally alternative to custody in prison. ${ }^{24}$ While data confirm the accuracy of the findings of earlier scholars - from Lombroso to Pollak — , reported above, it is women who are statistically more likely to harm their children, through cruelty or neglect. ${ }^{25}$ Often the harm remains hidden, and it is discovered only when external bodies detect its signs. ${ }^{26}$ Where arrests and convictions occur, gender bias in sentencing continues to be detected. ${ }^{27}$ But maternal violence carries hefty social and personal costs: it is extensive, and has a significant social impact, including financial costs and cumulative developmental consequences for the victims. ${ }^{28}$

In considering a body of fictional works in which the experiences of atypical mothers are represented, we have identified and selected a number of instances worth investigating 
which, in terms of genre, fall under the subgenre of 'psychological thriller' and, more specifically, 'domestic noir'. ${ }^{29}$ The novels come from three different European cultures, and were published between the end of the $20^{\text {th }}$ century and the present. In our first example, maternal violence is inspired by a sense of justice: the mother acts against her own child to protect society from the danger the child is considered to pose. This is what happens in Laura Grimaldi's Suspicion (2003 [1996]), a novella in which the protagonist kills her son, whom she

believes to be a serial killer, ostensibly to stop him causing further harm to society. ${ }^{30}$ In our second text, Véronique Olmi's Beside the Sea (2010 [2003]), the protagonist is a mother defeated by life, who kills her children as an act of mercy aimed at protecting them from the even worse harm that life itself would inflict on them. ${ }^{31}$ Our final instance, Clare Mackintosh's I Let you Go (2014), presents a perceptive study of gender violence, maternal guilt and grief, through a case of motherhood denied. ${ }^{32}$ All three stories foreground a dysfunctional familial dimension, in particular the relationship of the female protagonist to her (male) children, paying attention to the introspective element, and to the psychological investigation, which claims a privileged place in the architecture of the narrative. All three authors engage in a radical act of exposure (in I Let You Go) or subversion (in Suspicion and Beside the Sea) of culturally and socially accepted givens - especially those concerned with the enactment of maternal love, the representation of the mother-child bond and woman's agency and responsibility towards her children in violent households - exploding myths and exposing wounds in the process.

\section{Saving the world from the child, or the child from the world - Laura Grimaldi's Suspicion (2003 [1996]) and Véronique Olmi's Beside the Sea (2010 [2003])}

Both Suspicion and Beside the Sea portray mothers who are isolated, and who, relying only on themselves as trustworthy interlocutors, design a route to conflict resolution that requires the murder of their own offspring. Both appear to be variants of the model of mother labelled in psychoanalysis as 'fusional', and identified by the inability to accept the natural evolution in her relationship with her child, including acceptance of the child's right to its own individual 
existence. ${ }^{33}$ Grimaldi's protagonist Matilde Monterispoli, a woman whose sense of self-worth has always been a function of the men in her life (her late father and husband, and her son Enea), fits the model of the over-indulgent fusional mother. She is herself constructed as a signifier of passivity, lack and absence, dispensing affection sparingly, and only as a way of compensating for her own need to be mothered. The unnamed mother in Olmi's novel, conversely, appears to reify the phallic mother model - ostensibly empowered beyond what her natural role and function would allow, until the paroxystic climax in which she claims the right to decide that her children should not continue to live. No space for father figures is allowed in either of the narratives other than a conjectural, and minimal, extradiegetic one: this means that no rational counterpoint to the irrational and destructive agency of the mothers enacted in the stories is provided in the texts, which therefore appear to posit the latter, rather unequivocally, as a site of negativity and destruction. It is our contention, however, that whilst appearing to 'toe the line of patriarchy', the texts problematize a set of long established cultural givens, exposing the inadequacies of the conventional psychodynamic paradigm - whose uncontested application they indeed resist - and introducing subversive elements that erode the foundations of primary socio-cultural axioms.

Laura Grimaldi's Suspicion was inspired by one of the most disconcerting criminal cases in recent Italian history: the case of the 'Monster of Florence', the serial killer (or gang) who terrorized Florence and its environs for a period of seventeen years, between 1968 and 1985. As a journalist, Grimaldi had written extensively on the case; and as a crime fiction expert, she had cooperated with the police in their efforts to build a criminal profile of the perpetrator(s), who remained at large. ${ }^{34}$ Suspicion sets the events against a clearly recognizable spatial, temporal and cultural background, but narrates them from an alternative perspective, replacing the official police or media narratives, to which audiences had become accustomed, with the intimate, private point of view from inside a family. This, together with the core theme of the novel, which is the protagonist's suspicion that the Florence serial killer could be her own son, and the plan she designs to stop his murderous streak, creates a powerful effect of estrangement and generates expectations in readers acquainted with the original events, who could reasonably hope for some exceptional reveal from an author known to be reliably informed. Except that the power and appeal of the novel is not so much in the prospect of a disclosure of the identity of the monster, nor in the confirmation that Matilde's own investigative skills - inspired by that infallible gift that is maternal intuition - are more resource efficient and effective than those deployed in police operations. It resides instead in the suggestion that the act of destroying her only son is the protagonist's first ever chance to assert 
her own agency - a chance that is cynically demeaned in the narrative through two essential developments. Firstly, the killing happens by stealth: having decided that her son must die, Matilde does not commit the murder herself, but only makes a minimal move that facilitates it. She tampers with his daily insulin injection, so that his death is effectively a suicide. As a result, her agency is defused by its reliance on an additional actor to realise its goal. Secondly, her dignity and value as the dispenser of justice is destroyed by the realisation that she had misread the signs of her son's culpability, and that his death was in vain, as he had no part in the Florence murders.

Contrary to the temporal, spatial and cultural anchoring provided in Suspicion, Beside the Sea denies the reader any connection with a recognisable backdrop, refraining even from naming the protagonist. The mother retrospectively narrates the story of a trip to a seaside resort with her two boys, aged nine and five. A holiday out of season and out of character ('We'd never been away for a holiday, never left the city, and suddenly life felt new, my stomach was in knots, [...] but I did my best, yes really my best, so the kids didn't notice anything. I wanted us to set off totally believing in it.', p.10, our emphasis) which, despite the narrator's best efforts (or perhaps precisely because of them), raises the suspicion both of the children and of the readers from the outset. The journey begins in the night-time ('so no one would see us', p.9) on an old, noisy and unheated bus, on its last run of the day. Their destination is a coastal town plagued by constant rain, where the hostility of the wet and cold weather is mirrored by the inhospitable dinginess of their hotel accommodation, by the unfriendliness of the people with whom they get in contact, and by the ominous paucity of their means of support. Their entire resources consist in loose change, which the mother keeps in a tin, and which is enough to buy the children hot chocolate and chips for dinner, and to pay for a few rides at the funfair. After the money has run out, the reader gets the sense that time also is running out for the family, a sensation heightened by the protagonist's inability to conceptualise it. She struggles with the idea of time as a shared system of reference ('Hard to believe it's exactly the same time for everyone at the same moment', p.77), she cannot account for her past, nor does she demonstrate a systematic understanding of the present. The narrative offers no memories of the mother's life before the events she narrates ('I am not used to memories', she says; and 'memories don't always help', p. 99), with the exception of vague recollections of her father singing to her when she was a child, of social workers appointed to look after her case, and of the doctor's surgeries where she got her prescriptions. The absence of a defined background, and the availability of such sparse and random glimpses into the narrator's past, prevents the reader from making definite assumptions about her character and her fractured state of mind, and from anticipating 
the possible course of her actions. A similar effect is achieved by the protagonist's understanding of the present, which is entirely subjective and unreliable: she seeks imaginary spaces where she can retreat, subtracting herself from the real world and its rhythms ('I waited in all that bustle, that turmoil, that rushing, trying to find a quiet corner to lay my eyes [...] and eventually I found it: up in the sky there was a big wheel full of whoops and screams, I settled on that and didn't let go', p.82). She repeatedly wonders what time it is, offering only the rain, the cold, darkness and mud as potential points of reference, confounding the readers, and rendering their efforts to give the events narrated some order, a place along an objective chronological scale, entirely futile. In jarring contrast to her indeterminacy, the pragmatism of the children, who worry about the repercussion of this unauthorised absence from school, and about souvenirs to take back to the teachers, provides a tenuous link with normality, with common sense, and safety, which tragically snaps in the final pages of the novel. After preparing them for the night ('because at night there's a special preparation, like before a journey', p. 91) and tucking them into bed, the protagonist smothers them with a pillow, one after the other. She hopes that in death they will be together, but observing their dead bodies, facing away from each other, she realises that ' $[t]$ hey weren't joined together in death, they had lost each other there' (p. 105). And her scream at this realisation concludes the novel.

\section{The 'dysfunctional mother' as a useful scapegoat: psychosocial myths, responsibility and guilt in Clare Mackintosh's I Let you Go (2014).}

Clare Mackintosh's I Let You Go provides a complex reflection on guilt with relation to the (impossible) 'myth of motherhood'. Deeply engrained in Western public discourse, this model has engendered dangerous expectations towards mothers as well as perverse blaming mechanisms, which easily turn into self-blame, feelings of inadequacy and pain. ${ }^{35}$ The weight of responsibility, however, is rarely accompanied by an increase in power within the family, but is generally paired with public scrutiny and hasty judgement. ${ }^{36}$ 
This complex interplay is fictionalised by Mackintosh's novel, which explores the psychosocial pressures on a(n abused) woman's identity and agency when her motherly function becomes erroneously over-emphasised and the burden of responsibility becomes unbearable. The story is told by different, alternating voices offering fragments of facts presented from different perspectives that, taken together, enable the reader to reconstruct the full set of events. A short extradiegetic prologue introduces the case of a terrible hit-and-run, from which the narrative unfolds. The victim, a four-year-old boy, is left to die in his mother's arms. The investigation into the accident is carried out by a team led by DI Ray Stevens, the main focaliser of the sections narrating the police enquiry. Interestingly, and in line with the typical traits of domestic noir, besides following the investigation, the procedural sections linger on the details of DI Stevens' personal and family life: his midlife crisis, a difficult relationship with his teenage son - whom Stevens realises he does not know at all - and with his wife, a frustrated stay-at-home mum who resents her husband's total absorption with his job. Most of the novel is focused on the autodiegetic narrative of the female protagonist, Jenna, who, following a traumatic personal experience decides to escape to an isolated cottage in Wales to start over, reinventing herself with a new job and a very private life. Readers link Jenna to the hit-and-run of the incipit, and assume her narrative to be that of the grief stricken single mother of the dead boy. This assumption lasts until the police pay her a visit to her hideout in Wales, when Jenna's relation to the accident is revealed: she is not Jacob's mother, but the driver of the car that killed him. At this climactic point, a third, autodiegetic, narrator is introduced who, through long analeptic segments interspersed in the text, fills the gaps in Jenna's past that the narrative had left out, and adds a further perspective on the events. The perspective is that of Ian, Jenna's abusive estranged husband, who in a narrative directly addressed at his wife reveals the physical and psychological violence he inflicted on her, which culminated in a ferocious beating that caused the death of their unborn son. Progressively the character of Jenna transitions from that of a woman who killed someone's child, to a victim who has herself suffered the death of her own child.

In this novel the analysis of motherhood - or, rather, its violent impairment - and the way in which issues of blame and guilt related to mothering are dealt with, is significant. Jenna recognises the blame and guilt for what has happened to Jacob right from the start. Readers are induced to accept such feelings of guilt, and to understand the public vilification to which Jenna is subjected, apparently for not taking enough care of her son, for not preventing his death. This perception is in line with Western myths of motherhood, built on the belief that it is natural for mothers to love their children, to take care of them and, most poignantly, feel responsible for 
what happens to them. Linked to these cultural assumptions is a socially-constructed set of prescriptions on how women ought to behave. ${ }^{37}$ And when a mother does not conform to this ideal, society feels free to criticise and reproach her, adding to her own tangled feelings of guilt and self-blame. On her bus journey to her refuge in Wales, Jenna is troubled by the image of the young boy whose death she could not prevent: 'A woman sits next to me. She opens her newspaper and suddenly it feels as though someone is pressing on my chest. Jacob's face stares at me; bruised eyes rebuking me for not protecting him, for letting him die' (p. 15). Readers are made to feel what Jenna is feeling, and to share the view expressed by the woman on the bus, who apportions the blame for the accident equally between the reckless driver and the careless mother: 'Terrible, isn't it [...] Driving off like that without stopping [...] Mind you, [...] five years old. What kind of mother allows a child that age to cross a road on his own?' (p. 16).

The novel also introduces a series of additional issues that become closely intertwined: beyond the presumed maternal negligence, we see the aggravating factors of single motherhood, and of 'foreignness'. The readiness to blame the dead boy's mother for letting go of her son's hand at the point of crossing the road - which Jenna's legal team try to use as a factor to mitigate against Jenna's guilt as a presumed killer by dangerous driving - is reported in the novel as coming from all quarters. This is intensified when the identity and personal circumstances of the dead boy's real mother are fully revealed: a single parent, whose child was the result of a casual relationship, and a Polish immigrant. The reproach that comes from the public is shared by the young Polish mother herself, who considers herself deserving of the tragedy that has befallen her. In an intensely focalised segment, readers are told that '[w]hen Jacob was killed she felt it was her punishment for not telling [her parents]. [S]he's carrying around a lot of guilt over the whole thing' (p. 187).

When Jenna's own personal circumstances emerge, blame and guilt thicken and stratify, and she, too, has to face adverse reactions from multiple quarters: the angry protesters waiting for her outside of court; the people in the small Welsh village; and the police, stunned by her lack of emotion and trying to provoke her out of her apparent impassiveness ('It must have been tough for you [...] living with what you'd done', p. 178).Except that Jenna's confession after her arrest does not convince them, and further investigation uncovers the real dynamics of the events, and the real identity of the driver, exonerating Jenna from the crime.

The narrative suggests that punishment for a crime she had not committed was for Jenna a preferable option to being free, but placed again at the mercy of a dangerously violent husband. However, a close reading of the novel reveals the complexity of Jenna's guilt, suggesting that her confession is, more poignantly, a form of self-punishment for the loss of 
her child. In an entirely familiar psychological process blurring the boundaries between the statuses of victim and perpetrator, Jenna convinces herself that in the death of her son she is guilty by joint enterprise: had she not provoked Ian he would not have kicked her in the stomach, killing their unborn child: 'all I could think of was that if I hadn't burnt that shirt, Ben would still be alive' (p. 338). Jenna gives birth to a stillborn child, her body bears the marks of motherhood, even if she is denied the actual possibility of mothering. Motherhood becomes a strong part of Jenna's identification: 'I think of my son; [...]; of the ache in my womb that has never left. I think there should be a word for a mother with no children; for a woman bereft of the baby that would have made her whole' (p. 314). Not having the strength to leave her abusive husband adds to the unbearable sense of guilt and self-blame - all the more disabling as it is endorsed by society.

At the end of the novel, the question of female agency appears further problematised. On the one hand the protagonist realises that she has found the strength to fight back against domestic violence: 'I have spent most of my adult life hiding; running; being afraid, and now, as I'm feeling safe, he has come back to take it away from me. I will not let him. [...] And I don't run. I have run enough from him' (p. 358). In the concluding pages of the novel, their final fight ends with Ian falling off a cliff, presumably to his death, which marks the end of Jenna's oppression. On the other hand, society again denies her agency, thus also showing that institutional and private justice do not necessarily coincide: to protect her, and spare her further suffering, the police decide to file Ian's death as an accident. Merciful as this act may seem, honourable as far as our instinctive idea of justice is concerned, and in line with the observed practices of institutional leniency towards women, it annuls Jenna's active role in killing the man, her autonomous decision of fighting back, and thus public acknowledgement of her free and empowering choice.

\section{What makes a mother a 'bad mother'}

The novels analysed in this chapter leave the reader to ponder on a wide range of issues beyond the crime they place at the core of their plots. Foremost of these is the nexus between the justice sought or obtained, for different reasons, by the protagonists - which would appear to validate the destructive power of human obsessions and well-established social myths and expectations - and justice in the statutory sense - which would call for exemplar retribution in all their cases. The novels stage different articulations of problematized motherhood, showing mothers who have abdicated appropriate parental responsibilities and have withdrawn into a 
microcosm of their creation. The resultant distortion between external and internal realities offers a painful insight into the human condition and into the life of these female protagonists, who are profoundly lonely, deserted by those around them, and by society.

In Suspicion and Beside the Sea it is not the murders that are the most tragic event, rather the mise en scène of the tragic dynamics at work within the reputedly 'safe' microcosm of the family, and the victims left in their trail. ${ }^{38}$ The two mothers ostensibly act like the insidious Mother Goddess, the reification of the tragic archetype of Medea: they kill their children so that they can reclaim the control that they deem to have lost. Rather than a form of empowerment, however, murder is an act of desperation, performed to rescue themselves and their children from the inevitable suffering they consider that the world is going to inflict on them all. These mothers ultimately fall out of the 'mad' or 'victim' stereotypes, providing interesting case studies for the analysis of motherly behaviours which escape deeply entrenched - but limited and limiting - social assumptions, and myths of tame motherly love. I Let You Go shows yet another facet of the complex performance of motherhood, which is linked with a different kind of crime. Isolated like Olmi's unnamed mother and Grimaldi's Matilde, and withdrawn into the comfortable lies of a narration built to escape a reality that has become unbearable, Jenna's story too calls for a reflection on the issue of victimhood and victimisation, without reducing it to a blanket justification for female violence and 'unmotherly behaviour'.

By presenting the reader with different, complicated expressions of feelings of blame, guilt and responsibility linked with motherhood, the novels succeed in problematizing the socio-cultural status quo, exploring the overwhelming pressure of social expectations on mothers, and the social dysfunctions that can prevent a serene experience of motherhood. And by representing women who, in the end, reclaim ownership of their own narratives, the three novels make the reader stare at the kind of devastation that can occur when women attempt to resolve the tension between female agency, motherhood and victimhood without an open and equanimous cultural context to support them in this process. 
${ }^{1}$ Susan E. Chase and Mary Frances Rogers, Mothers and Children: Feminist Analyses and Personal Narratives, (New Brunswick: Rutgers University Press, 2001); Shulamith Firestone, The Dialectic of Sex: The Case for Feminist Revolution, (New York: Morrow Quill Paperbacks, 1970); Adrienne Rich, Of Woman Born:

Motherhood as Experience and Institution, (New York: Norton, 1976).

${ }^{2}$ Arguably the most sensationalised case in the UK is that of Myra Hindley, was convicted in 1965 for the abduction and murder of five children, and who died in jail in 2002. Hindley was considered as the epitome of female monstrosity, that had to be excised from society: although she engaged with psychiatric rehabilitation programmes while in jail, she was always denied parole. More recently, public shock was caused by the cases of Karen Matthews, who in 2008 kidnapped her own daughter to claim ransom money; and Vanessa George, a nursery nurse convicted for taking indecent images of young children in her care, which she passed to a known paedophile. Although in all three cases there was strong evidence that the women were under some form of coercion from male accomplices, the full force of social contempt and condemnation fell on them, ultimately guilty of not complying with the normative definition of femalehood and motherhood.

A summary overview of the most sensationalised cases of filicide in Italy seems to suggest that women act on their own accord. The case that has possibly generated the strongest public outcry is the so-called Cogne murder in 2002, where a mother was convicted for bludgeoning her toddler son to death. The initial life sentence was commuted to house arrest after six years in prison.

In the majority of reported cases of filicide, the press attribute to the mothers' mental health issues - normally depression or psychotic conditions - the root cause of the violence. The cases of sexual abuse or child neglect, conversely, are statistically more likely to involve men: mothers become complicit by not denouncing the crimes, for shame or for fear of being abandoned by the offender, usually their partner.

${ }^{3}$ Nicole Rafter, 'Crime, Film and Criminology Recent Sex-Crime Movies', Theoretical Criminology, 11 (2007).

${ }^{4}$ Derek Raymond, The Hidden Files (London: Little, Borwn and Company, 1992); Caroline Reitz, Detecting the Nation: Fictions of Detection and the Imperial Venture (Columbus: Ohio State University press, 2004);

Maurizio Ascari, A Counter-History of Crime Fiction: Supernatural, Gothic, Sensational (London; New York: Palgrave Macmillan, 2007).

${ }^{5}$ This is the thesis supported by Dorothy Roberts in 'Motherhood and Crime', Social Text, (1995). A case of a fictional work which has become a reference for criminology scholars is the series The Wire (2002-2008). See

David Lewis, Dennis Rodgers and Michael Woolcock, 'The Fiction of Development: Literary Representation as a Source of Authoritative Knowledge', The Journal of Development Studies, 44.2 (2008), 198-216.

${ }^{6}$ Rafter, p. 415.

${ }^{7}$ Cesare Lombroso and Guglielmo Ferrero, The Female Offender, Introduction by W. Douglas Morrison (New York: Appleton, 1899 [1893]); William Isaac Thomas, Sex and Society: Studies in the Social Psychology of Sex, (Chicago: University Press; London: T. Fisher Unwin, 1907).

${ }^{8}$ Sigmund Freud, New Introductory Lectures on Psycho-Analysis, trans. by Walter John Herbert Sprott

(London: L. and Virginia Woolf at the Hogarth Press, and the Institute of Psycho-analysis, 1933).

${ }^{9}$ Otto Pollak, The Criminality of Women, (Philadelphia, Pa.: University of Pennsylvania Press, 1950).

${ }^{10}$ Chantal Lavergne, Marie Jacob, and Claire Chamberland, 'Contributions Féministes À La Compréhension Des Mauvais Traitements Envers Les Enfants [Feminist Contributions to the Understanding of Child Maltreatment]', Violence envers les femmes et les enfants en contexte familial: Théories explicatives et données empirique, 69e Congrès de l'ACFAS, University of Sherbrooke, (2001). There are a number of other studies that investigate the complex dynamics of female violence, all pointing away from the simplistic notion of the impossibility for women to offend, but falling outside the scope of our discussion. Of particular interest are the studies of Steven Box and Steve Hale 'Liberation and Female Criminality in England and Wales', The British Journal of Criminology, 23 (1983) and Sandra Walklate, Gender and Crime: An Introduction (Belfast: Prentice Hall/Harvester Wheatsheaf 1995), who put to the test the proposition that women's emancipation and liberation could be contributing factors that led to the increase in female offending. These studies found no evidence of causal connections and disputed the contention as an argument aimed at minimising the achievements of the women's liberation movement. Michele Burman, 'Girls Behaving Violently?', Criminal Justice Matters, 53.1 (2003), and Amy Reckdenwald and Karen F. Parker, 'The Influence of Gender Inequality and Marginalization on Types of Female Offending', Homicide Studies, 12 (2008) investigated the links between violent female offenders and the role of sex in socialisation processes, as well as the impact of socio-economic marginalisation on the type of female offending. Following the principles of control theory (which proposes the idea that our tendency to deviate depends on the strength of our two control systems - inner controls and outer controls - and their ability to regulate our desire to obtain personal gains through deviation from social norms), Pat Carlen (Women, Crime and Poverty, Milton Keynes: Open University Press, 1988) has demonstrated that for some women crime can be 'liberating', a route to a more satisfying (albeit atypical) lifestyle than that afforded by the conventional labour and marriage markets, 
or by welfare payments. This view echoes earlier findings that showed that weak social bonds, and a weakened sense of commitment, attachment, involvement and belief, mean that engaging in criminal activity, against gender expectations, offers better rewards to women than a fulfilling a caring role at home. See Travis Hirschi, Causes of Delinquency, (Piscataway: Transaction publishers, 2002).

${ }^{11}$ See Shulamith Firestone, The Dialectic of Sex: The Case for Feminist Revolution, (New York: Morrow Quill Paperbacks, 1970); Adrienne Rich, Of Woman Born: Motherhood as Experience and Institution (New York: Norton, 1976). See also Chase and Rogers (2001).

${ }^{12}$ See Nancy J. Chodorow, The Reproduction of Mothering : Psychoanalysis and the Sociology of Gender (Berkeley; London: University of California Press, 1978), and Elisabeth Badinter and Roger DeGaris, The Myth of Motherhood: An Historical View of the Maternal Instinct, A Condor Book (London: Souvenir Press (E\&A), 1981). For De Beauvoir, see for example the novels Mémoires d'une jeune fille rangée ([Memories of a Dutiful Daughter] Paris: Gallimard, 1958), Une mort très douce ([A Very Easy Death] Paris: Gallimard, 1964), and the chapter on motherhood in Le deuxième sexe, ([The Second Sex] Paris: Gallimard, 1949).

${ }_{13}$ Brid Featherstone, 'Taking Mothering Seriously: The Implications for Child Protection', Child and Family Social Work, 4 (1999); Rozsika Parker, 'The Production and Purposes of Maternal Ambivalence', in Mothering and Ambivalence, ed. by Wendy Hollway and Brid Featherstone (London; New York: Routledge,1997), 17-36.; Wendy Hollway and Brid Featherstone, Mothering and Ambivalence (London; New York: Routledge, 1997).

${ }^{14}$ Dominique Damant et. al, 'Taking Child Abuse and Mothering Into Account. Intersectional Feminism as an Alternative for the Study of Domestic Violence', Affilia: Journal of Women and Social Work, 23.2 (2008); Leslie McCall, 'The Complexity of Intersectionality', Signs: Journal of Women in Culture and Society, 30.3 (2005); Kerry Carrington, 'Girls and Violence: The Case for a Feminist Theory of Female Violence', International Journal of Crime, Justice and Social Democracy, 2.2 (2013).

${ }^{15}$ For the first definition of intersectionality as a concept that brings into focus the nuances of all systems of oppression, see Kimberlé Crenshaw's "Demarginalizing the Intersection of Race and Sex: A Black Feminist Critique of Antidiscrimination Doctrine, Feminist Theory and Antiracist Politics". University of Chicago Legal Forum (1989), 139-167, p. 140.

${ }_{16}$ McCall, p. 1780.

${ }^{17}$ Brid Featherstone, 'Victims or Villains? Women Who Physically Abuse Their Children', in Violence and Gender Relations: Theories and Interventions, ed. by Barbara Fawcett, Brid Featherstone, Jeff R. Hearn and Cristine Toft (London: Sage, 1996), 178-189, p. 183.

${ }^{18}$ Damant et. al, p. 127.

${ }^{19}$ Parker, p. 18.

${ }^{20}$ Parker, p. 25.

${ }^{21}$ Parker, p. 25.

${ }^{22}$ Belinda Morrissey, 'Crises of Representation, or Why Don't Feminists Talk About Myra?', Australian Feminist Law Journal, 16 (2002); Tracey Peter, 'Mad, Bad, or Victim? Making Sense of Mother-Daughter Sexual Abuse', Feminist Criminology, 1 (2006); Hilary Allen, 'Rendering Them Harmless: The Professional Portrayal of Women Charged with Serious Violent Crimes', in Gender Crime and Justice, ed. by Pat Carlen and Anne Worrall (Milton Keynes: Open University, 1987).

${ }^{23}$ A report published by the Ministry of Justice in 2014, presenting data for England and Wales shows that, in the year 2013, women represented $18 \%$ of all arrests made, and $25 \%$ of convictions (Ministry of Justice,

Statistics on Women and the Criminal Justice System 2013, November 2014. Available at

$<$ https://www.gov.uk/government/uploads/system/uploads/attachment_data/file/380090/women-cjs-2013.pdf > [accessed 10 November 2016]). In 2015, women represented around $\overline{5} \%$ of the overall prison population in the UK. See also <http://www.womeninprison.org.uk/research/key-facts.php $>$ [accessed 11 November 2016].The data is in line with historical trends. See also Mike Hough, Jessica Jacobson, and Andrew Millie, The Decision to Imprision: Sentencing and the Prison Population (London: Prison Reform Trust, 2003)

${ }^{24}$ Ibid. See also data from the Italian National Institute of Statistics, which compares Italian data with data from the other countries of the European Union <http://www.istat.it/it/files/2015/03/detenuti-2015-

1.pdf?title $=$ Detenuti + nelle+carceri + italiane+-+19\%2Fmar\%2F2015+-+Testo+integrale.pdf. $>$ [ accessed 11 November 2016].

${ }^{25}$ The data is available for the UK. See the graph in the Ministry of Justice report, p. 65, which shows that cruelty or neglect of children accounts for roughly $13 \%$ of the crimes of 'violence against the person' committed by women, and $1 \%$ ca of the same category of crimes committed by men.

${ }^{26}$ This is the situation described by the Italian National Observatory on the Health of children and adolescents (Paidòss) in a 2014 report. Data from 300 paediatricians who had observed signs of ill treatment in their young patients shows that $80 \%$ of the cases of unreported child abuse in Italy are perpetrated by mothers. Whilst we acknowledge the limitation of this report (because of the small number of respondents and the limitation of the sample to children who were taken to be seen by a paediatrician), its findings invite some reflection on the role of mothers in children's wellbeing. Curiously, the first systematic report on child abuse in Italy, produced by the 
National Observatory on Childhood and Adolescence does not provide significant information on the (gender of the) perpetrator of the abuses. See

$<$ http://www.garanteinfanzia.org/sites/default/files/documenti/Indagine_maltrattamento_TDH_Cismai_Garante mag15.pdf $>$ [Accessed 14 November 2016].

${ }^{27}$ The Ministry of Justice report observes that ' $[\mathrm{t}]$ he type of sentence outcome given at court differs between male and female offenders'. More specifically, '[t] he most common disposal given to male offenders [for offences including cruelty to or neglect of children] is an immediate custodial sentence', whereas, by contrast, 'the most common disposal given for the offenc[e] of [...] cruelty to or neglect of children was a community sentence'. Statistics on Women and the Criminal Justice System 2013, pp 65-66. Our emphasis. Available at $<$ https://www.gov.uk/government/uploads/system/uploads/attachment_data/file/380090/women-cjs-2013.pdf> [ accessed 11 November 2016].

28 See Judi Pears and Patricia Noller, 'Youth Homelessness: Abuse, Gender and the Process of Adjustment to Life on the Streets', The Australian Journal of Social Issues, 30 (1995). This study cites maternal violence as one of the prime causes of youth homelessness. Kimberly A Tyler and Ana Mari Cauce finds mothers responsible for one third of the first acts of physical violence against children in 'Perpetrators of Early Physical and Sexual Abuse among Homeless and Runaway Adolescents', Child abuse \& neglect, 26 (2002)

${ }^{29}$ Julia Crouch, Genre Bender (2013), <http://juliacrouch.co.uk/blog/genre-bender> [accessed 18 November 2016].

${ }^{30}$ Laura Grimaldi and Robin Pickering-Iazzi, Suspicion, (Madison, Wis.: University of Wisconsin Press, Terrace Books, 2003). [1996]

${ }^{31}$ Véronique Olmi, Beside the Sea, (London: Peirene, 2010).

${ }^{32}$ Clare Mackintosh, I Let You Go, First Berkley Hardcover Edition. edn (New York: Berkley Books, 2016).

${ }^{33}$ See E. Ann Kaplan, Motherhood and Representation: The Mother in Popular Culture and Melodrama, (London; New York: Routledge, 2013) p. 47. In Freudian psychoanalysis, and in its subsequent developments, the relationship between the child and the mother is divided into two phases: the pre-Oedipal, in which the child perceives no separation with the mother's body, experiencing a sense of fusion with her, and the post-Oedipal, when a separate sense of self develops, and separation occurs. Fusional motherhood is a psychopathological condition characterised by the mother's attempts to lock the child in a pre- Oedipal stage, preventing separation and individuation. The main types of fusional motherhood, widely represented in culture, are the self-sacrificing 'angel of the house', the overindulgent and the phallic. See also Marianne Hirsch, The Mother/Daughter Plot: Narrative, Psychoanalysis, Feminism (Bloomington: Indiana University Press, 1989).

${ }^{34}$ Although an arrest was made for the murders, the doubt whether the man convicted was in fact the Monster of Florence remained (and possibly still does), generating a number of conspiracy theories and alternative hypotheses.

${ }^{35}$ See Parker: 'Despite the power of unconscious processes, our society continues to have grandiose expectations of mothers. And mothers, with their profound desire to be good mothers, both reproduce and resist these expectations. Wanting to control the uncontrollable, a mother feels painfully culpable when things go wrong' (p. 34).

${ }^{36}$ Parker says 'Yet, even while mothers are accorded overwhelming responsibility for their children's development, their authority is all the time circumscribed, subjected as they are to the critical gaze of a network of social structure' (p. 34).

${ }^{37}$ Peter, p. 283.

38 See Elvio Guagnini, 'Alcuni esemplari recenti di giallo italiano dentro e fuori gli spazi istituzionali', in Problemi, 86 (1989): 257-288, p. 281. 